\title{
The mechanical properties of saline ice under uniaxial compression
}

\author{
Gary A. Kuehn and Erland M. Schulson \\ Ice Research Laboratory, Thayer School of Engineering, Dartmouth College, Hanover, NH 03755-8000, U.S.A.
}

\begin{abstract}
Understanding the mechanical properties of saline ice is important for engineering design as well as for operations in polar regions. In order to gain understanding of the basic mechanisms of deformation and fracture, laboratory-grown columnar saline ice, representative of first-year sea ice, was tested in uniaxial compression under a variety of conditions of strain rate $\left(10^{-7}\right.$ to $\left.10^{-1} \mathrm{~s}^{-1}\right)$, temper-ature $\left(-40^{\circ},-20^{\circ},-10^{\circ}\right.$ and $\left.-5^{\circ} \mathrm{C}\right)$ and orientation (loading vertically or horizontally: i.e. parallel or perpendicular to the growth direction). The range of strain rate spanned the ductile-to-brittle transition for every combination of temperature and specimen orientation. The results of over 250 tests are reported. Mechanical properties, failure mode and ice structure are analyzed with respect to the testing conditons. The results show that strength is dependent upon the ice structure, orientation, strain rate and temperature. During loading in the ductile regime the structure is altered (e.g. by recrystallization), whereas in the brittle regime the majority of the structural change is through cracking. The results are compared to results from the literature on both natural sea ice and laboratory-grown saline ice. Where possible, they are interpreted in terms of micromechanical models.
\end{abstract}

\section{INTRODUCTION}

An understanding of the uniaxial compressive properties of saline ice is an important basis from which to begin to understand the more complicated scenarios found in nature, such as the forces exerted by a floating ice feature against an offshore structure, or the extent of pressure ridging during the interaction between ice floes. This paper is a contribution to such understanding.

The first studies on the compressive strength of sea ice consisted of both field and laboratory tests from field specimens (Butkovich, 1956, 1959; Peyton, 1966; Schwarz, 1970; Wang, 1979; Sinha, 1981, 1983, 1984; Frederking and Timco, 1980, 1983, 1984). In more recent studies some investigators have used laboratory-grown saline ice (LGSI) to model sea ice in a more economical and controlled manner (Richter-Menge, 1986). The LGSI is grown under reproducible conditions and the material and mechanical properties are similar to those of first-year sea ice.

The present study uses LGSI to examine the mechanical properties under a variety of conditions of strain rate $\left(10^{-7}\right.$ to $\left.10^{-1} \mathrm{~s}^{-1}\right)$, temperature $\left(-40^{\circ},-20^{\circ}\right.$, $-10^{\circ}$ and $-5^{\circ} \mathrm{C}$ ) and orientation (loading vertically or horizontally; i.e. parallel or perpendicular to the growth direction). The overall objectives are to create as complete a picture as possible of the mechanical properties and to obtain some insight into the deformation processes of saline ice. As will be seen, the trends and observations apparent from this study are similar to those previously reported from smaller data sets from both natural and artificial material. The novel feature is that, to the authors' knowledge, this is the most complete investigation over such a wide range of conditions on material of one origin. The brittle regime was more thoroughly investigated in this study than in earlier studies and the ductile to brittle transition was considered in terms of the underlying micromechanics. In the ductile regime recrystallization was observed at every temperature $\left(-5^{\circ}\right.$ to $\left.-40^{\circ} \mathrm{C}\right)$ in both vertical and horizontal oriented samples.

\section{EXPERIMENTAL PROGEDURE AND ICE STRUCTURE}

LGSI was grown by freezing a $23 \%$ saline solution (using a commerical salt mixture, "Instant Ocean", which contains, in the proper proportions, the salts found in natural sea water) unidirectionally downward using an aluminum cooling plate through which glycol circulates on top of an $8171,915 \mathrm{~mm}$ diameter Nalgene tank. The $23 \%$ solution prevents excess salinity of the solution towards the end of the growth period. The process typically takes about $15 \mathrm{~d}$ to produce a puck of approximately $300 \mathrm{~mm}$ thickness. Figure 1 shows the ice puck thickness and cooling plate temperature versus time.

The ice structure was characterized by three regions: a granular region which extended for roughly $2 \mathrm{~cm}$ from the top surface; a columnar structure which extended almost to the bottom surface; and a region where the freezing was incomplete which created a high porosity, "skeletal 


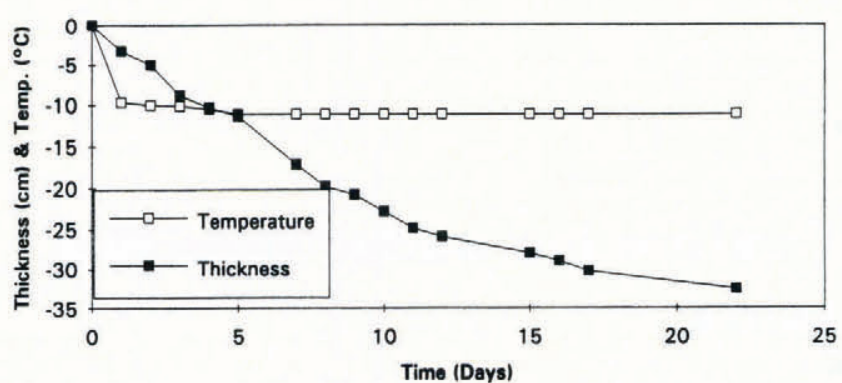

Fig. 1. Laboratory-grown saline ice growth profiles of thickness and cooling plate temperature vs time.

layer" near the bottom of the puck. To avoid variations in microstructure, the test samples did not contain material from either the granular or the skeletal regions. Also, no specimens were taken from within $5 \mathrm{~cm}$ of the sides of the puck. The average equivalent column diameter, AECD, $\left(D_{\text {Ave }}=[4 A / \Pi]^{1 / 2}\right.$, where $A$ is the average grain area determined from a thin section) was used to characterize the "grain-size" throughout the columnar region of the puck, Table 1. The grain-sizes were similar to those of natural sea ice.

The ice contained brine pockets arranged in a

Table 1. Average equivalent column diameter vs depth in ice puck

$\begin{array}{lllll}\text { Depth }(\mathrm{cm}) & 4.5 & 15.0 & 22.5 & 33.0\end{array}$

$\mathrm{AECD}(\mathrm{mm}) \quad 1.9 \pm 0.3 \quad 3.2 \pm 0.4 \quad 4.7 \pm 0.4 \quad 5.7 \pm 0.4$ platelet-like manner along the basal planes with a spacing of 0.5 to $1 \mathrm{~mm}$. The spacing did not vary noticeably throughout the depth of the puck. Salinity was determined by melt-water conductivity. Density was determined at $-10^{\circ} \mathrm{C}$ by comparing the weight of the ice in air to that in iso-octane. A new technique (which will be described in detail in a separate note) of sealing porous ice samples with a solid ice coating was used to prevent the iso-octane from penetrating the sample upon immersion. Without the ice coat, the density determination of porous samples by immersion overestimates values by approximately $0.3 \%$. Porosity (gas + brine volume) was calculated as described by Cox and Weeks (1982). Typical profiles of salinity, density, gas volume and brine volume are shown in Figure 2. The $c$-axes were unaligned and within $\pm 15^{\circ}$ of the horizontal plane (i.e. roughly perpendicular to the growth direction).

About 20 cores of $102 \mathrm{~mm}$ diameter of either vertical or horizontal orientation (with the long axis parallel or perpendicular to the growth direction, respectively) were obtained from each puck. Cores were stored at or below $-25^{\circ} \mathrm{C}$ (i.e. at a temperature below the $\mathrm{H}_{2} \mathrm{O}-\mathrm{NaCl}$ eutectic) and subsequent temperature changes were completed over at least a $48 \mathrm{~h}$ period. All samples were machined at $-10^{\circ} \mathrm{C}$. The ends of each sample were milled perpendicular to the long axis. Typical parallelism of the ends was between 0.025 and $0.051 \mathrm{~mm}$, corresponding to 0.00025 and 0.0005 rad. Sample lengths ranged from 156 to $311 \mathrm{~mm}$. The variations in sample length had no apparent effect on the strength or failure characteristics.

Throughout the course of this work three different sample-loading train interfaces were used: direct contact with metallic (brass) brush platens, brush platens with a "dental dam" latex insert, and synthane end-caps bonded to the sample. However, for most of the tests (i.e. for all
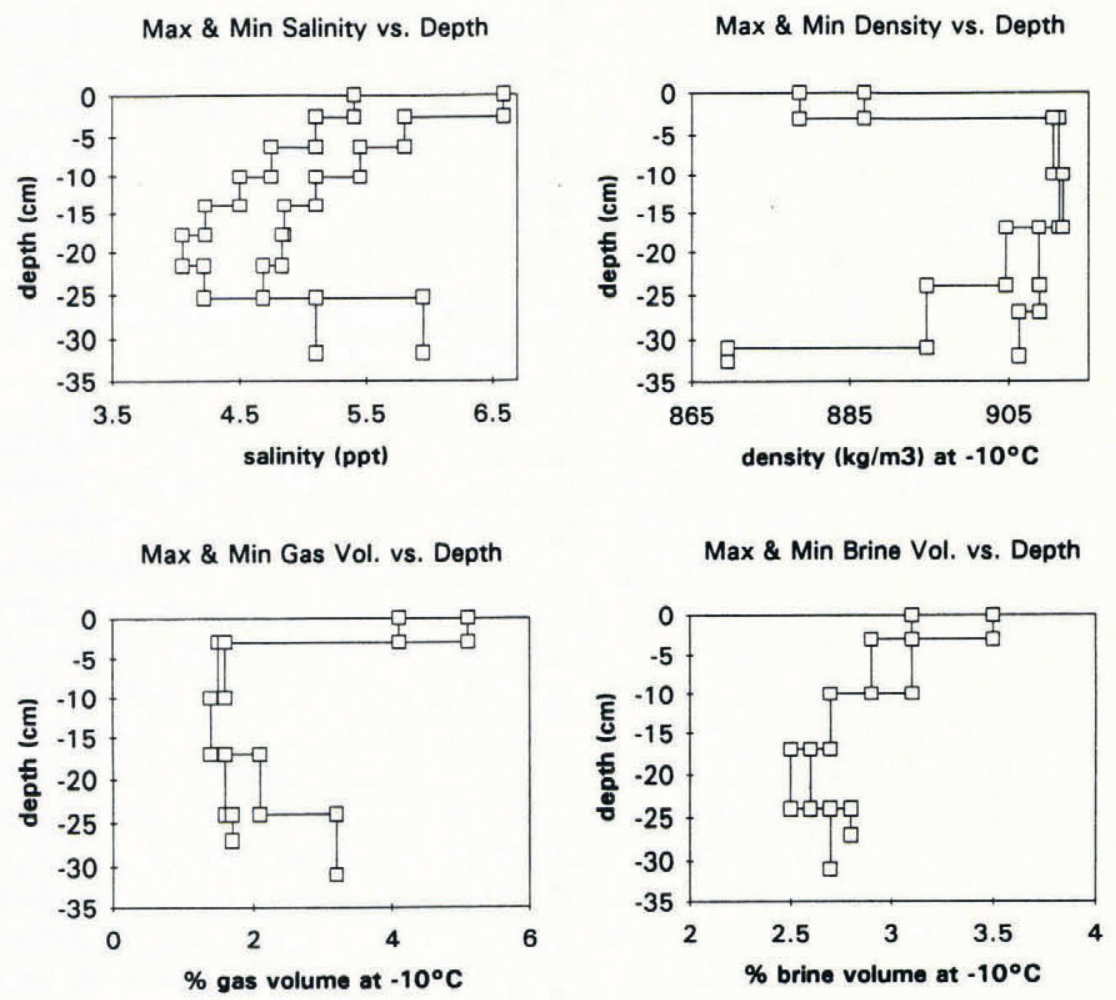

Fig. 2. Typical laboratory-grown saline ice profiles of salinity, density, gas and brine volume vs depth in the ice puck. 
the tests at $-5^{\circ} \mathrm{C},-20^{\circ} \mathrm{C}$, and most at $-40^{\circ} \mathrm{C}$, and for some at $-10^{\circ} \mathrm{C}$ ) the brush platens were used because they allow the most truly uniaxial loading condition (Lasonde and others, 1988). The addition of the latex sheet had no effect on either the strength or the failure mode. Tests were performed under uniaxial compression at strain rates from $8.9 \times 10^{-7} \mathrm{~s}^{-1}$ to $3.0 \times 10^{-1} \mathrm{~s}^{-1}$ by loading both along the columnar grains (vertical orientation) and perpendicular to the columns (horizontal orientation) at temperatures of $-5^{\circ},-10^{\circ},-20^{\circ}$ and $-40^{\circ} \mathrm{C}$. A PC-based data acquisition system was used to collect load, strain, actuator displacement and time. Strain was measured using extensometers which were mounted either on collars attached to the synthane end-caps, on the brush platens or directly on the ice. Although the different methods of attachment affected the strain measurement, the difference had no noticeable affect on the strength of the ice.

More detailed descriptions of the experimental procedure and of the characterization of the material techniques are given elsewhere (Kuehn, 1993).

\section{RESULTS AND DISGUSSION}

\section{Stress-strain behavior}

Figure 3 shows the compressive stress-strain curves for both horizontally and vertically oriented specimens deformed at $-10^{\circ} \mathrm{C}$. The shape of the curves and the trends apparent were similar for the other three

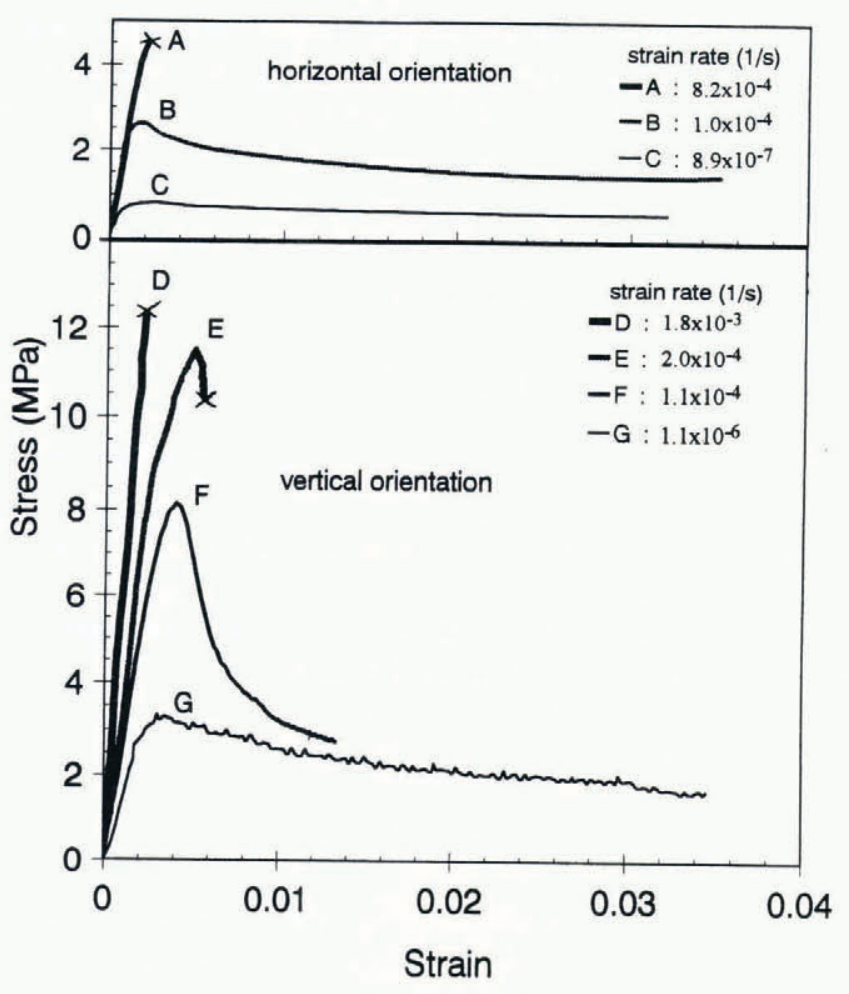

Fig. 3. Stress-strain curves of laboratory-grown saline ice at $-10^{\circ} \mathrm{C}$ of horizontal and vertical orientations at a range of strain rates from $8.9 \times 10^{-7}$ to $1.8 \times 10^{-3} \mathrm{~s}^{-1}$. The " $X$ " on curves $A, D$ and $E$ denotes fracture. The trends that the curves show are also typical of the other temperatures, $-40^{\circ},-20^{\circ}$ and $-5^{\circ} \mathrm{C}$. temperatures. At high strain rates the ice was brittle and the curves (A and D) were nearly linear, terminating in fracture. As the strain rate decreased and approached the brittle-to-ductile transition, the curves for samples which failed in the brittle regime showed some curvature as well as an abbreviated peak before fracture (see curve E). At low strain rates, the ice was ductile: the stress first increased, reached a peak and then decreased to almost a constant stress level, i.e to nearly a plateau (curves B, C, F and $\mathrm{G}$ ).

Tests within the ductile regime were terminated after roughly $3 \%$ shortening through an operator-controlled unloading of the specimens. It is possible that a plateau would have been seen in all cases of ductile behavior had some of the specimens been deformed further. The strain softening occurred more rapidly in the vertial orientation than in the horizontal orientation for a given strain rate (compare curves $\mathrm{B}$ and $\mathrm{F}$ ). The ratio of the plateau strengths from the vertical to the horizontal orientations was smaller than the ratio of the peak strengths from the vertical to the horizontal orientations. This suggests that, for a given strain rate, some form of steady-state was developing, independent of the loading direction. Also, the stress reduction decreased as the strain rate decreased, to a point where little if any peak was observed (curves C and $G$ ). It is likely that the peak reflects the onset of dynamic restorative processes such as recovery and recrystallization and that the plateau reflects a more or less steady-state microstructure. This is discussed further under 'Ductile regime' below.

\section{Ductile-to-brittle transition}

As will become apparent, the transition from ductile to brittle failure marks the point of greatest compressive strength. Figure 4 shows the transition strain rate versus temperature for both vertical and horizontal orientations. The transition rate was obtained from both the transition in the shape of the stress-strain curve (i.e. from one showing only a rising branch (AD; Fig. 3) to one showing both rising and descending branches (B, C, F, G; Fig. 3)) and from the failure mode (described in the next section). Generally, a range of strain rates marked the transition, and not one particular value. Hence a range of values is shown. The transition strain rate was generally higher by approximately an order of magnitude in horizontally oriented ice than in vertically oriented ice. The effect of temperature is less clear, but two possible patterns could be discerned: either there is little change in the transition strain rate from about $-5^{\circ}$ to $-20^{\circ} \mathrm{C}$ followed by a decrease at $-40^{\circ} \mathrm{C}$; or the transition strain rate decreases continuously with decreasing temperature over the whole range.

The ductile-to-brittle transition strain rate is roughly an order of magnitude greater in columnar saline ice than in fresh-water columnar ice of the same grain-size (Batto and Schulson, 1993). The origin of this difference as well as the transition itself can be understood within the context of the micromechanical model proposed by Schulson (1990). Accordingly, the transition from ductile to brittle behavior is attributed to the suppression of timedependent (i.e. creep) deformation at the tips of internal microcracks and, thus, to the onset of crack propagation. 


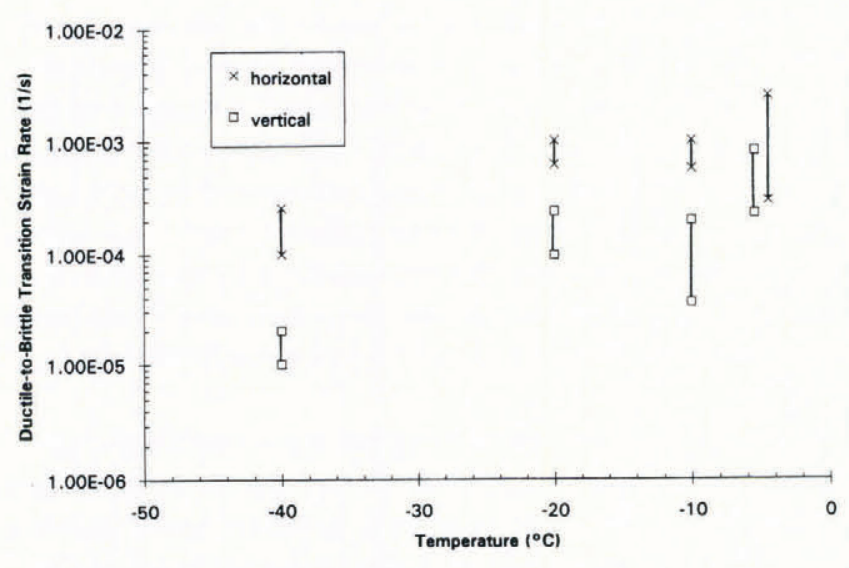

Fig. 4. The ductile-to-brittle transition strain rate of horizontally and vertically oriented LGSI vs temperature.

The transition strain rate, $\dot{\epsilon}_{D / \mathrm{B}}$, can then be expressed in terms of a set of parameters which incorporate creep deformation, fracture toughness, ice/ice friction and microstructural size. Specifically,

$$
\dot{\epsilon}_{D / \mathrm{B}}=\frac{4 Z \mathrm{~A} K_{1 \mathrm{C}}{ }^{3}}{3 \pi \mathrm{f}(1-\mu) \lambda^{3 / 2}},
$$

where A is the constant in the power law expression for creep $\left(\dot{\epsilon}=\mathrm{A} \sigma^{n}\right), K_{1 \mathrm{C}}$ is the fracture toughness, $\mu$ is ice ice friction coefficient and $\lambda$ is the microstructural size that sets the length of the parent, internal crack; $Z$ is a dimensionless experimental parameter which relates the brittle fracture strength to $K_{1 \mathrm{C}}, \mu$ and $\lambda$, and $\mathrm{f}$ is a dimensionless constant which relates the diameter of the crack-tip creep zone to the microstructural size. Of these parameters the one most likely to differ for the saline ice is A, being about one order of magnitude higher for this material than for fresh-water ice. (This difference is based upon a comparison of the B-parameter for both materials, where $B$ relates the ductile failure strength to the strain rate (see 'Ductile failure strength' below); and the comparison is with Sinha's data (1981) for fresh-water columnar ice.) Hence the greater ductile-to-brittle transition strain rate. Interestingly, the transition strain rate (personal communication from H. Eicken, J. A. Richter-Menge and M. Lange) for more finely grained saline ice (albeit, granular sea ice $)$ is higher than that reported here $\left(\sim 10^{-3}\right.$ to $10^{-2} \mathrm{~s}^{-1}$ vs $8 \times 10^{-4} \mathrm{~s}^{-1}$ for horizontal orientation), in qualitative accord with the model. Parametric values for horizontally oriented ice at $-10^{\circ} \mathrm{C}$ are as follows: $\mathrm{A}=\mathrm{B}^{-1 / m}=$ $1.1 \times 10^{-5} \mathrm{MPa}^{-3} \mathrm{~s}^{-1}$ (where $\mathrm{B}$ and $m$ are given under 'Ductile failure strength' below), $K_{1 \mathrm{C}} \simeq 0.1 \mathrm{MPa} \cdot \mathrm{m}^{1 / 2}$ (Parsons and others, 1986, for sea ice), $\mu \simeq 0.5$ (Jones and others, 1991), $\lambda \simeq 3 \mathrm{~mm}$ (from the length of parent, sliding cracks shown in Smith and Schulson, 1994), $Z \simeq 2.5$ (Schulson, 1990, albeit for fresh-water ice) and $\mathrm{f} \simeq 0.02$ (Batto and Schulson, 1993); these values lead to a predicted transition strain rate of $\dot{\epsilon}_{D / \mathrm{B}} \simeq 5 \times 10^{-3} \mathrm{~s}^{-1}$ which is in rough agreement with the present observations.

\section{Failure characteristics}

Table 2 summarizes the failure characteristics for the samples tested using the brush platens. We focus on the brush platens because, as noted above, they were the ones which produced the most truly uniaxial loading and so were the ones used to investigate the behavior at all temperatures. The characteristics depended upon sample orientation and strain rate, but not upon temperature. Synthane end-caps (which impart a laterally confining

Table 2. Uniaxial compressive failure characteristics of LGSI

\section{Ductile regime}

\section{Horizontal \\ orientation \\ (loading across columns)}

Vertical orientation

(loading along columns)
Displacement perpendicular to columns, initially evenly distributed throughout the sample, with the appearance of voids and greater regions of shear becoming noticeable at strains greater than 0.005 .

Bands and recrystallized grains visible in thin sections.

Localized deformation or bulging usually at one end (where column diameter is larger), or both ends, with some, but few, crosscolumn cracks.

Axial cracks $1 / 2$ or less of sample length at higher strain rates.

Bands and recrystallized grains visible in thin sections.
Axial cracking and shear failure on planes parallel to the long axis of the columns; some, but very little, cross-column cracking, evenly distributed throughout

Axial cracking (i.e parallel to the loading direction) with cross-column cracks. The majority of the cracks were perpendicular to the columns (surrounded by column boundaries), but some cracks were inclined. 
stress) caused barreling of both horizontally and vertically oriented ductile samples and caused shear faulting of horizontally oriented brittle samples. Barreling was not seen with the brush platens, even when specimens were shortened by as much as $8 \%$ (Lasonde and others, 1988). Although the different boundary conditions produced different failure characteristics, they produced no discernible difference in the strength, for a given strain rate.

\section{Ductile regime}

Figure $5 \mathrm{a}$ and b illustrates the characteristics of ductile deformation for ice slowly loaded perpendicular to the columns. Voids were seen at higher strains, i.e. beyond the peak and near to the plateau (Fig. 5a). The deformation of the horizontally oriented ice was probably caused principally by intragranular crystallographic slip on favorably oriented basal planes. Grain (column) boundary sliding may also have contributed, but its relative contribution was not ascertained. The voids may
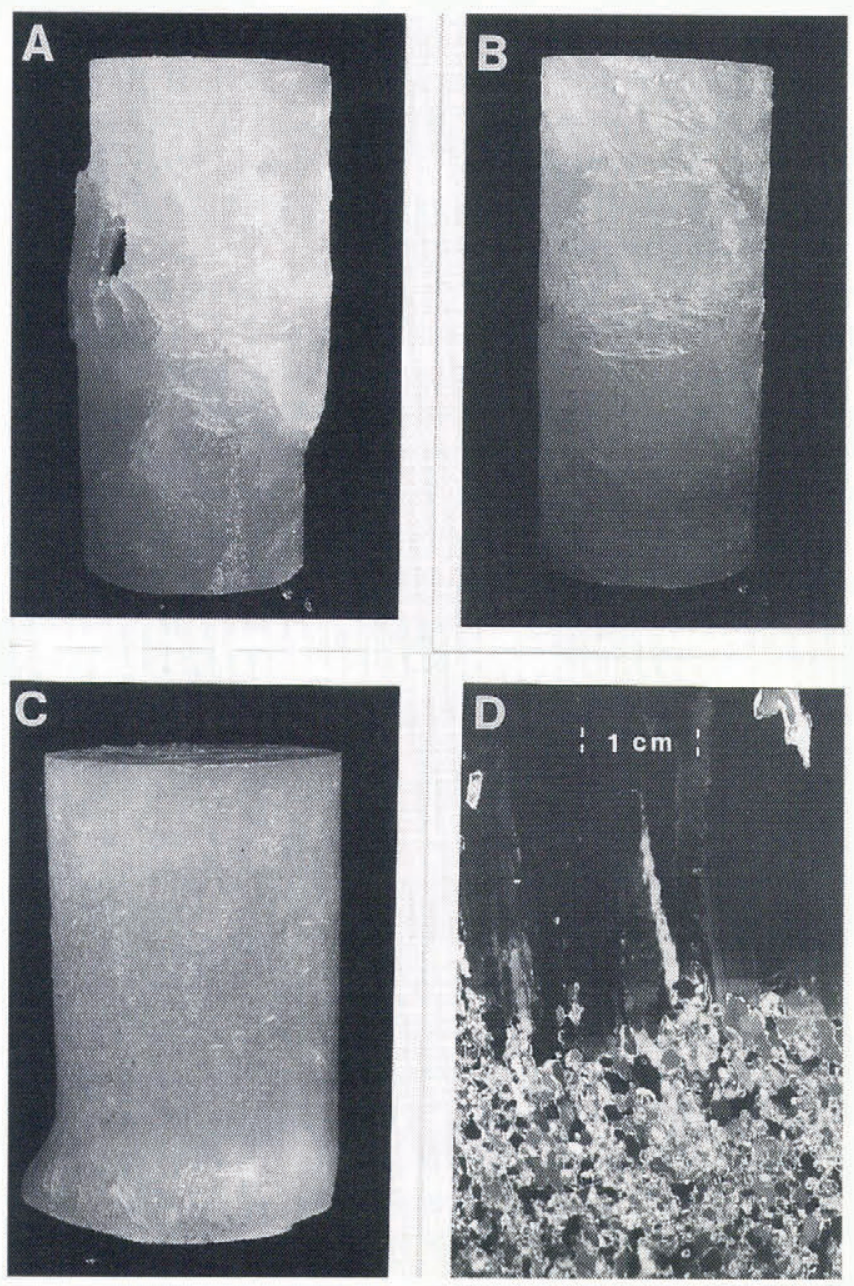

Fig. 5. Photographs of ductile specimens. a, horizontal orientation; the long axis of the columnar grains run in and out of plane of paper. Note the void and the displacement across the columnar grains $\left(T=-5^{\circ} \mathrm{C}, \dot{\epsilon}=8 \times 10^{-5} \mathrm{~s}^{-1}\right.$, $\epsilon=0.031) . b$, as a, rotated $90^{\circ}$ about axis of specimen. Note absence of displacement along the columnar grains. $c$, Vertical orientation. Note the bulge or "foot" near the bottom of the specimen $\left(T=-5^{\circ} \mathrm{C}, \dot{\epsilon}=1 \times 10^{6} \mathrm{~s}^{-1}\right.$, $\epsilon=0.031 . d$, vertical thin section of $c$. Note the recrystallized grains in the "foot".
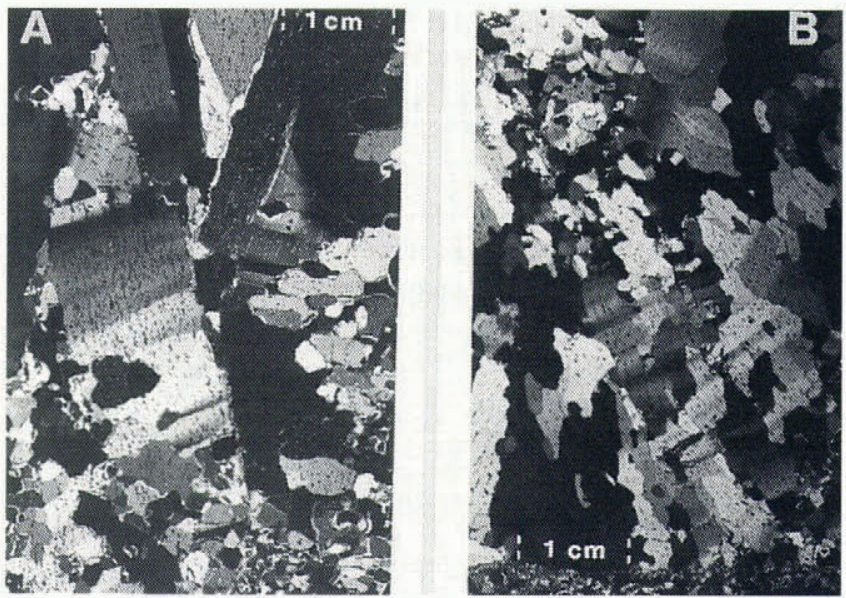

Fig. 6. Thin sections of a, vertically $\left(T=-10^{\circ} \mathrm{C}\right.$, $\left.\dot{\epsilon}=3 \times 10^{-6} s^{-1}, \epsilon=0.037\right)$ and $b$, horizontally ( $\left.T=-10^{\circ} \mathrm{C}, \epsilon=3 \times 10^{-5} \mathrm{~s}^{-1}, \epsilon=0.038\right)$ oriented LGSI compressed aboul $3 \%$ in the ductile regime. Both sections show a few columns (longitudinal (a) and cross sections (b)) similar to those of undeformed ice bordered by regions of banding and recrystallization.

reflect different basal plane orientations in adjacent columns with one grain being favorably oriented to slip and the other not.

The ductile deformation of the vertically oriented ice (Fig. 5c,d) occurred preferentially in localized areas. With the synthane end-caps the deformation was localized to either a shear band which bulged out at the surface (similar to the one apparent for the horizontally oriented ice, Fig. 5a) or a displacement of the columns through bending outward. When the brush platens were used, the deformation appeared like a "foot" or bulge (Fig. 5c) at the sample ends; this feature occurred most often at the bottom end of the sample which corresponded to the lower part of the parent ice puck. Regardless of platen type, in every case the localized area of deformation was recrystallized, whether within a shear band or within a "foot". This feature can be seen in Figure 5d.

Every ductile specimen of both orientations, even those deformed at $-40^{\circ} \mathrm{C}$, showed bands and recrystallized grains in post-test thin sections. These sections were made as soon as possible (within about $30 \mathrm{~min}$ ) from specimens strained beyond the peak, and are assumed to display the actual deformation structure and not some post-test features which are irrelevant to the mechanical behavior of the material. Figure $6 \mathrm{a}$ and $\mathrm{b}$ shows typical microstructures, from vertically and horizontally oriented samples, respectively. Note that the grains which contain the bands border the recrystallized regions. The bands were similar to those seen by Steinmann (1958) in warm $\left(-1.9^{\circ} \mathrm{C}\right)$ granular fresh-water ice slowly deformed at $10^{-5} \mathrm{~s}^{-1}$ and by Knight (1962) and by Nathanson (reported by Knight, 1962) in arctic sea ice. They are also similar to the kink bands which form in fresh-water columnar ice during creep deformation at $-9.5^{\circ} \mathrm{C}$ (Gold, $1963)$.

The bands in the sea ice were attributed to the formation of sub-grains under thermal stress (Knight) and to uniaxial compressive deformation (Nathanson). In 
the columnar, fresh-water ice they were explained in terms of the formation of sub-grain boundaries through a dislocation process (Gold). In the present work, many thin sections were examined. In every case the bands were oriented more or less normal to the platelet-like array of brine pockets, analogous to their being perpendicular to the basal slip lines in the fresh-water ice (Gold). Since the brine-pocket array lies along the basal planes, this alignment means that the walls separating the bands are roughly normal to the basal planes. In view of their orientation, the bands are probably sub-grains which resulted from the development during straining of a polygonized microstructure, as commonly seen in hotworked metals. In this regard, therefore, the salt-water and fresh-water materials are similar. Polygonization and
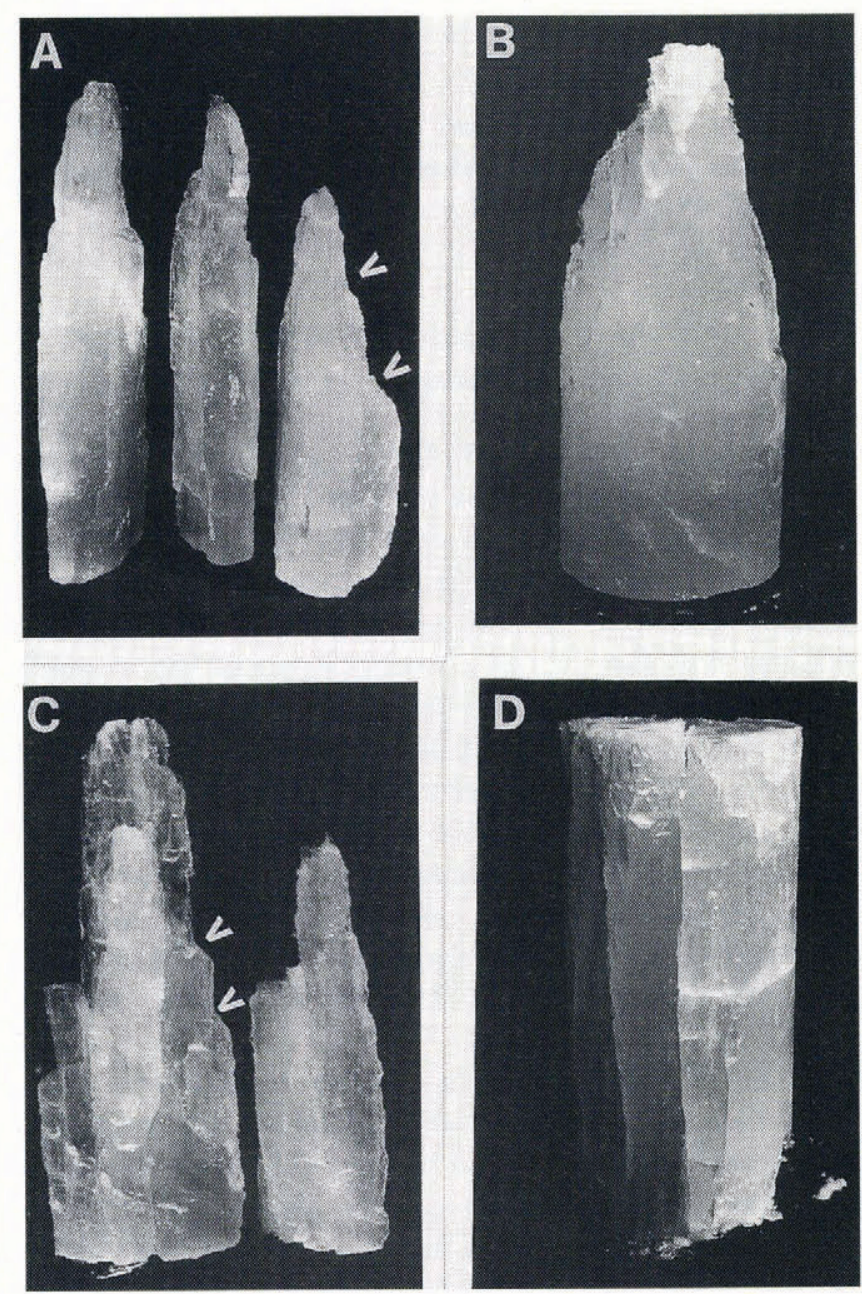

Fig. 7. Photographs of brittle failure specimens. $a$ and $b$, horizontally oriented LGSI which failed through axial cracking ( $a, T=-40^{\circ} \mathrm{C}, \dot{\epsilon}=1 \times 10^{-3} \mathrm{~s}^{-1}$ ). The arrows point to inclined steps. The cracks within other horizontally oriented samples linked to produce shear failure planes $\left(b, T=-5^{\circ} \mathrm{C}, \dot{\epsilon}=1 \times 10^{-2} \mathrm{~s}^{-1}\right)$; the columns run in and out of the page. $c$ and $d$, shards of $a$ vertical oriented LGSI sample (c, T $=-40^{\circ} \mathrm{C}$, $\left.\dot{\epsilon}=2 \times 10^{-5} \mathrm{~s}^{-1}\right)$ and a sample still intact $(d, T=$ $-40^{\circ} \mathrm{C}, \dot{\epsilon}=1 \times 10^{-3} \mathrm{~s}^{-1}$ ) show evidence of axial cracking. Both the edges of the shards (c) and central regions of the intact sample (d) show evidence of crosscolumn cracking. Note the steps on the fracture surface in $7 c$ (arrows). dynamic recrystallization often occur together in metals (Cahn, 1970) deformed at high temperatures and so it is not surprising to see evidence for both features in ice slowly deformed at temperatures above $80 \%$ of the melting point. Although evidence for their occurrence near the peak of the stress-strain curve has not been obtained, polygonization and recrystallization are probably important elements in the strain softening of saline ice.

\section{Brittle regime}

The brittle failure of horizontally oriented samples occurred through either axial splitting (i.e. along the loading direction) or macroscopic shear faulting, Figure 7. It is likely that the shear zones observed in some specimens are a result of the linking of flaws such as brine channels and/or short axial cracks created during the loading. Both failure modes have been described by Smith and Schulson (1994) in their study on the failure of saline ice plates loaded biaxially across the columns under small degrees of confinement. It is interesting to note the inclined steps on the fracture surface (arrows, Fig. 7a). Smith and Schulson (1994) observed similar features and attributed them to the development of wing cracks through the operation of the frictional crack sliding mechanism analyzed by Nemat-Nasser and Horii (1982) and by Ashby and Hallam (1986).

The brittle failure of vertically oriented ice also occurred by axial splitting, i.e. parallel to the loading direction, Figure $7 \mathrm{c}$ and $\mathrm{d}$. The splits appeared to be a combination of intra- and inter-granular cracking. Often the axial cracks were linked together by cross-column cracks, which were usually perpendicular but sometimes inclined at about $45^{\circ}$ to the loading direction (see arrows, Fig. 7c). The perpendicular cracks probably formed as the result of rapid unloadling (see Couture and Schulson, 1994) once the specimen split, while the inclined cracks may have acted as parent cracks upon which sliding occurred and from the tips of which axial wings sprouted and grew into full-length splits.

\section{Mechanical properties}

\section{Failure strain}

Figure 8 shows the failure strain versus strain rate and orientation for each temperature. For ductile behavior, the strains correspond to the peak stress while for brittle behavior they correspond to the strain at specimen collapse. Within the ductile regime (to the left of the broken vertical lines) the failure strain rises with decreasing strain rate, while within the brittle regime it is lower and roughly independent of strain rate. To a first approximation, temperature appears to have little effect for a given strain rate and orientation. Similarly, orientation appears to have little effect, although the data are too scattered to allow a firm conclusion on this point.

\section{Compressive strength}

The strength of the ductile ice was taken as the peak stress. The strength of the brittle ice was taken as the brittle failure stress. The strength varied markedly with the strain rate, temperature, and sample orientation, 

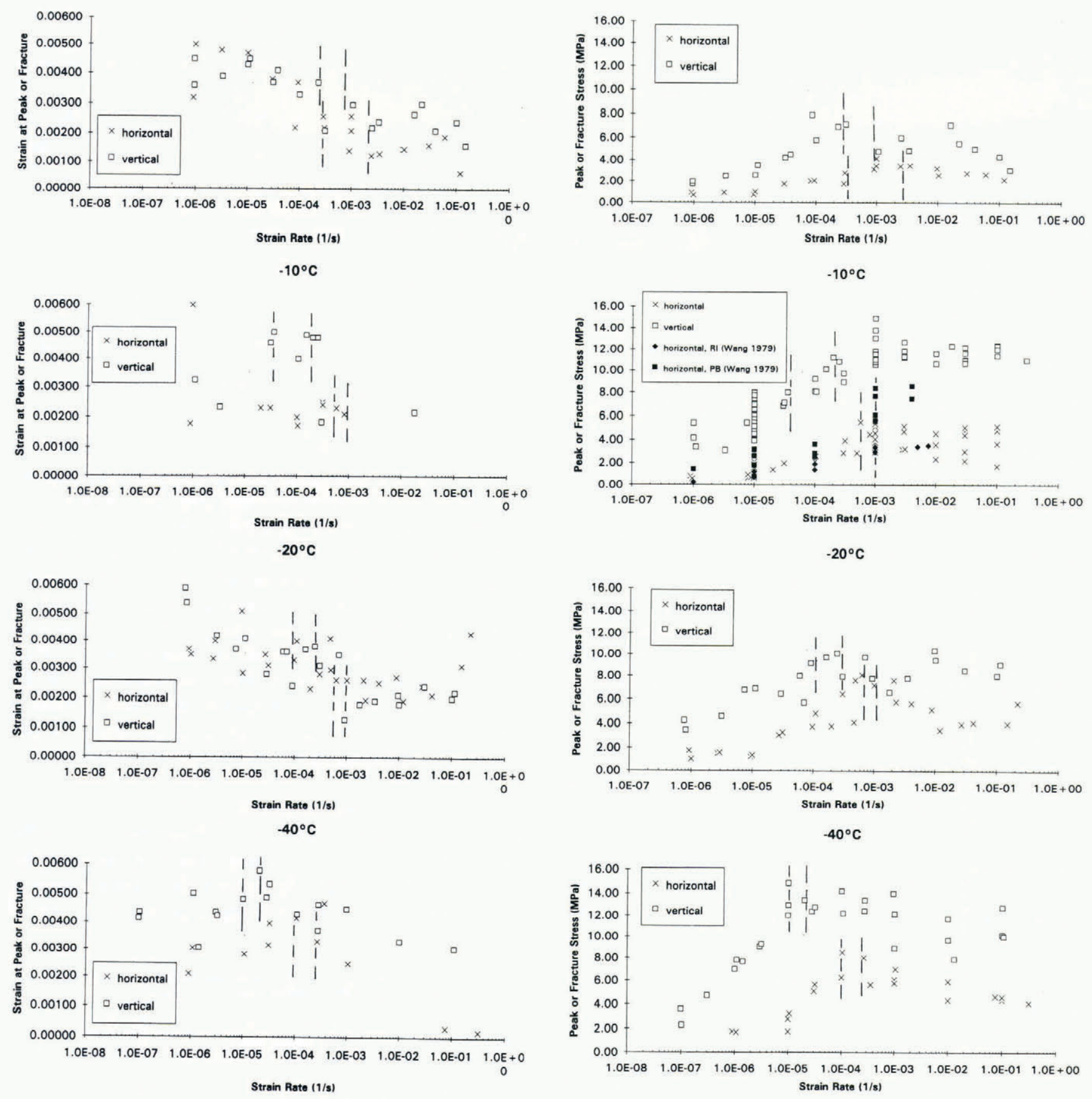

Fig. 8. The failure strain (strain at peak or fracture) vs strain rate for LGSI of horizontal and vertical orientations tested with brush platens at $-5^{\circ},-10^{\circ},-20^{\circ}$ and $-40^{\circ} \mathrm{C}$. The ductile-to-brittle transition regions of the vertical and horizontal orientations are between the broken vertical lines.

(Fig. 9). Although earlier work by Butkovich (1956, 1959), Peyton (1966), Schwarz (1970), Wang (1979), Frederking and Timco (1980, 1983, 1984), Sinha (1983,1984) and Richter-Menge (1986) has shown the importance of these variables, the present study perhaps shows the effects more comprehensively using one kind of ice. It is interesting to note that the data for the laboratory ice are similar to those for first-year sea ice (Wang, 1979), at least at $-10^{\circ} \mathrm{C}$ loaded across the columns. (Wang's data are plotted in Fig. 9b.) The

behavior is described below.

Ductile failure strength

For both orientations and at all temperatures, the strength, $\sigma_{\mathrm{d}}$, within the ductile regime increased with increasing strain rate, $\dot{\epsilon}$. The dependence can be described by the relationship

$$
\sigma_{\mathrm{d}}=\mathrm{B} \dot{\epsilon}^{m}
$$


Table 3. Strain-rate sensitivity, " $m$ " (Equation (2))

\section{Horizontal orientation Vertical orientation}

$\begin{array}{rll}-40^{\circ} \mathrm{C} & 0.33 & 0.32 \\ -20^{\circ} \mathrm{C} & 0.27 & 0.15 \\ -10^{\circ} \mathrm{C} & 0.32 & 0.18 \\ -5^{\circ} \mathrm{C} & 0.23 & 0.26\end{array}$

where $\mathrm{B}$ is a temperature-sensitive constant. The strainrate sensitivity exponent, $m$, was computed using leastsquares analyses from the data for each temperature and orientation, Table 3 . No consistent trend in $m$ is evident with either temperature or ice orientation, suggesting that the strength-limiting process is independent of these parameters over the ranges investigated. The average value is $m=0.26 \pm 0.05$, which is close to the value of 0.3 found for fresh-water columnar ice (Sinha, 1981) and for columnar sea ice (Sinha, 1983, 1984).

Concerning the effect of temperature, Figure 10 shows the ductile compressive strength at different strain rates. The values plotted are averages and were obtained from the data in Figure 9. For both orientations the strength increases with decreasing temperature, the effect being greater as the strain rate increases. Butkovich (1956, $1959)$ and Frederking and Timco $(1980,1984)$ previously reported this same trend from studies over a smaller range of temperature than used here.

Brittle failure strength

In the brittle regime the strength appeared either to be constant or to decrease slightly with increasing strain rate
Table 4. Ratio of strength of vertical to horizontal orientation, $\sigma_{\mathrm{v}} / \sigma_{\mathrm{h}}$

\begin{tabular}{rcccc} 
& & Ductile & & $\begin{array}{c}\text { Brittle } \\
\text { average }\end{array}$ \\
& $10^{-6} \mathrm{~s}^{-1}$ & $10^{-5} \mathrm{~s}^{-1}$ & $10^{-4} \mathrm{~s}^{-1}$ & \\
& & & & \\
\hline$-40^{\circ} \mathrm{C}$ & 4.4 & 4.3 & - & 2.1 \\
$-20^{\circ} \mathrm{C}$ & 2.7 & 2.0 & 1.5 & 1.7 \\
$-10^{\circ} \mathrm{C}$ & 7.5 & 5.4 & 3.8 & 2.9 \\
$-5^{\circ} \mathrm{C}$ & 2.6 & 2.8 & 3.0 & 1.3 \\
& & & & \\
\hline
\end{tabular}

(Fig. 9). Also, it increased with decreasing temperature (Fig. 10c,d). Since strain rate had only a small effect, the average strength from tests at all strain rates was plotted versus temperature for both orientations to illustrate the effect of temperature. Similar effects were reported by Richter-Menge (1986) in laboratory-grown ice and in first-year sea ice, by Cox and others (1985) in multi-year sea ice and by Schulson (1990) in fresh-water ice. That similar patterns are seen in both salt-water and freshwater ice implies that the behavior noted here is more a reflection of the ice per se than of an effect of the entrapped air and brine.

\section{Vertical versus horizontal orientation}

As apparent from Figure 9, in both the ductile and the brittle regimes the strength was greater along the columns than across the columns. Specifically, from the averages of the values shown in Figure 9, the ratio of the strength of

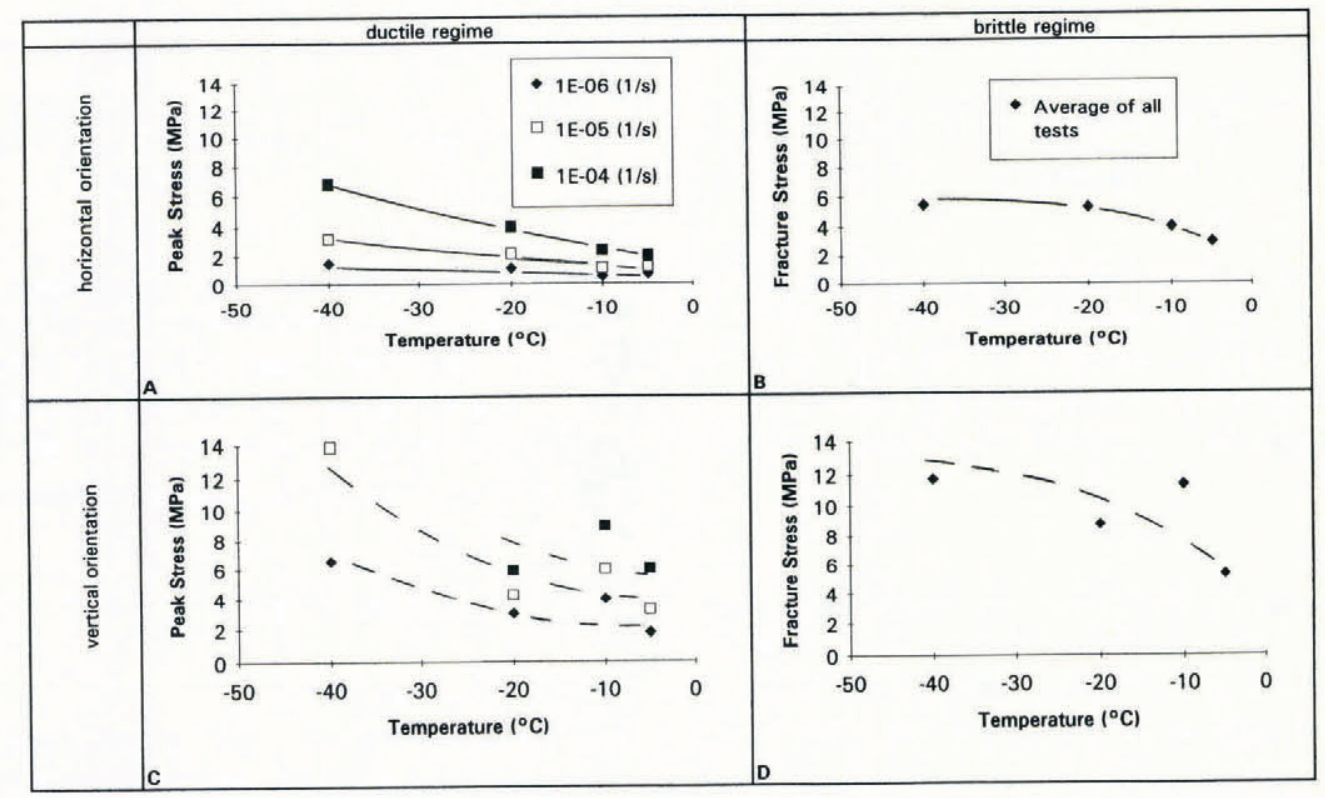

Fig. 10. Average peak (ductile regime) or fracture stress (brittle regime) vs temperature for horizontally and vertically oriented LGSI. In the ductile regime, for each temperature and orientation, peak stress values were taken from a least-squares line of the ductile test results from a separate log stress vs log strain-rate plot. In the brittle regime, for each temperature and orientation, the average fracture stress of all of the brittle test results was plotted. 
the vertically oriented ice to that of the horizontally oriented ice, $\sigma_{\mathrm{v}} / \sigma_{\mathrm{h}}$, for the ductile and the brittle regimes was $3.6 \pm 1.7$ and $2.0 \pm 0.7$, respectively, Table 4 . The ratio for the ductile strength is similar to that noted for columnar sea ice (Butkovich, 1959; Peyton, 1966; Frederking and Timco, 1984; Richter-Menge, 1986). No consistent variation with either temperature or strain rate is evident.

The origin of the greater strength along the columns than across the columns is different for the two regimes. Within the ductile regime, the difference can be explained in terms of the difference in the orientation of the basal planes on which crystallographic slip occurs. For the horizontal orientation there is always a high resolved shear stress on the basal planes in the slip direction in at least some grains so that, to a first approximation, the ductile failure strength across the columns, $\sigma_{\mathrm{h}}$, is about $2 \tau$ where $\tau$ is the shear stress on the basal planes at failure. For the vertically oriented samples the basal planes are inclined to the loading direction by a small angle, $\gamma$, owing to the fact (as noted under 'Experimental procedures and ice structure') that the $c$-axes were oriented up to $15^{\circ}$ out of the horizontal plane of the parent ice puck. As a result, there is a much smaller shear stress resolved on to the slip planes when the ice is loaded along the columns. In this case it can be shown that for small $\gamma$ the shear stress on the basal plane is given by the product of the applied compressive stress and $\gamma$, i.e. $\tau \approx \sigma_{\mathrm{a}} \gamma$. Then, by equating the shear stress at failure for both orientations and writing that $\tau \approx \sigma_{\mathrm{h}} / 2$, it follows that the ratio of the ductile failure strengths for the vertical to the horizontal orientations is given as $\sigma_{\mathrm{v}} / \sigma_{\mathrm{h}}=$ $1 / 2 \gamma$. For an average value of $\gamma$, say $\gamma=8 \pm 2^{\circ}$ (which is within the extremes measured), $\sigma_{\mathrm{v}} / \sigma_{\mathrm{h}}=3.6 \pm 1.0$, which agrees with the observations.

The origin of the difference in strength with orientation within the brittle regime is less clear. Possibly, it relates to an effect of orientation on the parameters which control the brittle compressive strength of ice (Schulson, 1990), such as fracture toughness, the ice/ice friction coefficient or the appropriate microstructural scale.

\section{GONGLUSIONS}

The following conclusions are drawn from a study of laboratory-grown columnar saline ice deformed under uniaxial compression at temperatures of $-40^{\circ},-20^{\circ},-10^{\circ}$ and $-5^{\circ} \mathrm{C}$, at strain rates from $10^{-7}$ to $10^{-1} \mathrm{~s}^{-1}$ both across (horizontal) and along (vertical orientations) the columns:

1. At every temperature and for both orientations there is a transition from ductile to brittle behavior upon raising the strain rate to a critical value.

2. The transition occurs over a narrow range of strain rate the center of which is about an order of magnitude lower for the vertical orientation; it varies from about $10^{-3} \mathrm{~s}^{-1}$ at $-5^{\circ} \mathrm{C}$ to about $2 \times 10^{-4} \mathrm{~s}^{-1}$ at $-40^{\circ} \mathrm{C}$ for the horizontal orientation and from about $6 \times$ $10^{-4} \mathrm{~s}^{-1}$ at $-5^{\circ} \mathrm{C}$ to about $2 \times 10^{-5} \mathrm{~s}^{-1}$ at $-40^{\circ} \mathrm{C}$ for the vertical orientation.

3. The transition strain rate can be explained in terms of a micromechanical model which incorporates creep, fracture, friction and microstructural scale.

4. For both orientations the ductile and the brittle failure strengths generally increase with decreasing temperature, while only the ductile strength increases with increasing strain rate.

5. The ratio of the vertical to horizontal strengths is $3.6 \pm 1.7$ in the ductile regime, as reported by Butkovich (1959), Peyton (1966), Frederking and Timco (1984) and Richter-Menge (1986) and $2.0 \pm 0.7$ in the brittle regime.

6. In every case of ductile behavior recrystallization occurred. The recrystallization was accompanied by microstructural bands which appear to be precursors to recrystallization and which are attributed to sub-grain formation through polygonization.

\section{ACKNOWLEDGEMENTS}

The experimental laboratory-grown saline ice program was initiated by Russell Lee with help from Dr Wilfrid Nixon. The initial techniques and equipment were adapted from those in practice at the Cold Regions Research and Engineering Laboratory and subsequently refined over several years by many graduate students at Thayer School. This work was sponsored by Office of Naval Research, grant no. N00014-92-J-1279. It was performed at the Ice Research Laboratory which is operated through additional support from Army Research Office, U.S. Coast Guard, Minerals Management Service, Conoco, Exxon, Mobil and MTS Corp.

\section{REFERENCES}

Ashby, M. F. and S. D. Hallam. 1986. The failure of brittle solids containing small cracks under compressive stress states. Acta Metallurgica et Materialia, 34(3), 497-510.

Batto, R.A. and E. M. Schulson. 1993. On the ductile to brittle transition in ice under compression. Acta Metallurgica et Materialia, $41(7), 2219-2225$.

Butkovich, T. R. 1956. Strength studies of sea ice. SIPRE Res. Rep. 20.

Butkovich, T. R. 1959. On the mechanical properties of sea ice, Thule, Greenland, 1957. SIPRE Res. Rep. 54.

Cahn, R. W. 1970. Recovery and recrystallization. In Cahn, R. W., ed. Physical metallurgy. North-Holland Publishing Co., 1129-1197.

Couture, M. L. and E. M. Schulson. 1994. The cracking of ice during rapid unloading. Philos. Mag. Lett., 69(1), 9-14.

Cox, G. F. and W.F. Weeks. 1982. Equations for determining the gas and brine volumes in sea ice samples. CRREL Rep. 82-30.

Cox, G. F. and 6 others. 1985. Mechanical properties of multi-year sea ice. Phase II: test results. CRREL Rep. 85-16.

Frederking, R.M.W. and G.W. Timco. 1980. NRC ice property measurements during the Canmar Kigoriak trials in the Beaufort Sea winter 1979 80. Ottawa, National Research Council of Canada. Division of Building Research. (Paper 947.

Frederking, R. M.W. and G.W. Timco, 1983. Uniaxial compressive strength and deformation of Beaufort Sea ice. In The Seventh International Conference on Port and Ocean Engineering under Arctic Conditions, Helsinki, Finland, 5-9 April 1983. Vol. 1. Espoo, Technical University of Finland, 89-98. 
Frederking, R. M. W. and G. W. Timco. 1984. Compressive behavior of Beaufort Sea ice under vertical and horizontal loading. In Lunardini, V.J., ed. Proceedings of the Third International Offshore Mechanics and Arctic Engineering Symposium ... Lousiana ... 1984. Vol. 3. New York, American Society of Mechanical Engineers, 145-149.

Gold, L. W. 1963. Deformation mechanisms of ice. In Kingery, W. D., ed. Ice and snow. Cambridge, MA, MIT Press, 8-27.

Jones, D. E., F. E. Kennedy and E. M. Schulson. 1991. The kinetic friction of saline ice against itself at low sliding velocities. Ann. Glaciol., 15, 242-246.

Knight, C. A. 1962. Polygonization of aged sea ice. 7. Geol., 70(2), 240 246.

Kuehn, G.A. 1993. Laboratory-grown saline ice-a first-year sea ice analog: the uniaxial compressive properties and the uniaxial tensile properties after compressive pre-strain. (M.S. thesis, Dartmouth College. Thayer School of Engineering.)

Lasonde, G.J., M. C. Gies and E. M. Schulson. 1988. The effect of end conditions on the strength and fracture of ice under compression. In Saeki, H. and K.-i. Hirayama, eds. Proceedings, the 9th International Symposium on Ice, 23-27 August 1988, Sapporo, Japan. Vol. 1. Delft, International Association for Hydraulic Research. Committee on Ice Problems, 99-108.

Nemat-Nasser, S. and H. Horii. 1982. Compression-induced nonplanar crack extension with application to splitting, exfoliation, and rockburst. J. Geophys. Res., 87(B8), 6805-6821.

Parsons, B. L., J. B. Snellen and B. Hill. 1986. Physical modeling and the fracture toughness of sea ice. In Lunardini, V.J., Y.S. Wang, O.A. Ayorinde and D. V. Sodhi, eds. Proceedings of the Fifth International Offshore Mechanics and Arctic Engineering (OMAE) Symposium ... Tokyo, Japan, April 13-18, 1986. Volume IV. New York, American Society of Mechanical Engineers, 358-364.
Peyton, H. R. 1966. Sea ice strength. College, AK, University of Alaska. Geophysical Institute. (UAGR-182.)

Richter-Menge, J. A. 1986. Comparison of the compressive behavior of naturally and laboratory-grown saline ice. In Ice Penetration Workshop, Monterey, CA, 331-350.

Schulson, E. M. 1990. The brittle compressive fracture of ice. Metallurgica et Materialia, 38(10), 1963-1976.

Schwarz, J. 1970. The pressure of floating ice-fields on piles. In I.A.H.R. Symposium. Ice and its Action on Hydraulic Structure, Reykjavik, Iceland, 7 10 September 1970, 6.3.

Sinha, N. K. 1981. Comparative study of ice strength data. In IAHR International Symposium on Ice, Québec, Canada, fuly 27-31, 1981. Proceedings. Vol. II. Québec, Université Laval, 581-592.

Sinha, N.K. 1983. Field tests on rate sensitivity of vertical strength and deformation first-year columnar grained sea ice. Ottawa, National Research Council of Canada. Division of Building Research.

Sinha, N. K. 1984. Uniaxial compressive strength of first-year and multiyear sea ice. Can. J. Civ. Eng., 11(1), 82-91.

Smith, T. R. and E. M. Schulson. 1994. Brittle compressive failure of salt-water columnar ice under biaxial loading. f. Glaciol., 40(135), $265-276$.

Steinmann, S. von. 1958. Experimental investigations of the plasticity of ice. Boston, MA, American Meteorological Society. (Translation AMST-G-166.)

Wang, Y. S. 1979. Crystallographic studies and strength tests of field ice in the Alaskan Beaufort Sea. In POAC 79; the Fifth International Conference on Port and Ocean Engineering under Arctic Conditions. ... Vol. 1, $651-665$.

The accuracy of references in the text and in this list is the responsibility of the authors, to whom queries should be addressed. 